\title{
Bioconstrucción de vivienda unifamiliar de interés social con caña Guadua angustifolia Kunth
}

\section{Bioconstruction of single-family social housing with bamboo Guadua angustifolia Kunth}

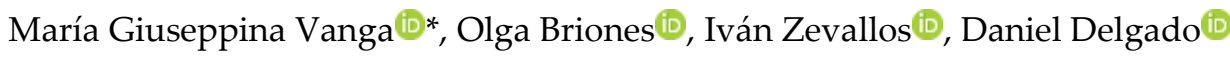 \\ Universidad Técnica de Manabí, Portoviejo, Ecuador, 130105; \\ olga.briones@utm.edu.ec; ivan.zevallos@utm.edu.ec; daniel.delgado@utm.edu.ec
}

Citación: Vanga, M. G., Briones, O., Zevallos, I., \& Delgado, D., (2021). Bioconstrucción de vivienda unifamiliar de interés social con caña guadúa para Manabí. Novasinergia. $\quad 4(1)$. 53-73. https://doi.org/10.37135/ns.01.07.03

Recibido: 12 abril 2020

Aceptado: 08 abril 2021

Publicado: 01 junio 2021

Novasinergia

ISSN: 2631-2654

\section{(c) (1) (3)}

Copyright: 2021 derechos otorgados por los autores a Novasinergia.

Este es un artículo de acceso abierto distribuido bajo los términos y condiciones de una licencia de Creative Commons Attribution (CC BY NC). (http://creativecommons.org/licens es/by/4.0/).
*Correspondencia: maria.vanga@utm.edu.ec

Resumen: El crecimiento de la población, el aumento de la necesidad de obtener una vivienda y el deterioro del medio ambiente hacen que el mundo necesite preservar el medio ambiente y ahorrar energía. Una alternativa ante este requerimiento es la utilización de materiales que contribuyan al desarrollo local y reduzcan los costos en la industria de la construcción. Este estudio pretende realizar una recopilación bibliográfica sobre los aspectos más relevantes de la construcción con el bambú Guadua angustifolia Kunth y elaborar una memoria descriptiva que sirva de referencia para su ejecución. Como resultado, se ha analizado y diseñado una vivienda unifamiliar construida principalmente con Guadua angustifolia Kunth bajo los parámetros exigidos por los organismos competentes en Ecuador en cuanto a tamaño y presupuesto. La ejecución de este tipo de proyectos con las recomendaciones y directrices emitidas sigue los principios de la bioconstrucción, promueve la arquitectura vernácula y contribuye a reducir la huella ecológica de la industria de la construcción. Los resultados sirven de documento orientador en la búsqueda de financiación para viviendas de bajo coste y como guía para la ejecución y supervisión de la obra. El objetivo es que estas propuestas constructivas se generalicen y que el bambú Guadua angustifolia Kunth se convierta en un material de múltiples aplicaciones para contribuir al problema de la vivienda en Ecuador.

Palabras clave: Arquitectura vernácula, Guadúa angustifolia Kunth, hábitat sostenible y sustentable, huella ecológica, industria de la construcción, material de construcción, viviendas de bajo costo, vivienda de interés social.

\begin{abstract}
The population growth, the increase in the need to obtain housing, and the deterioration of the environment make the world need to preserve the environment and energy-saving. An alternative to this requirement is using materials that contribute to local development and reduce costs in the construction industry. This study aims to carry out a bibliographic compilation on the most relevant aspects of construction with the bamboo Guadua angustifolia Kunth and prepare a descriptive report to serve as a reference for its execution. As a result, we have analyzed and designed a singlefamily house built mainly of Guadua angustifolia Kunth under the parameters required by the competent bodies in Ecuador in terms of size and budget. The execution of this type of project with the recommendations and guidelines issued follows the principles of bio construction, promotes vernacular architecture, and reduces the construction industry's ecological footprint. The results serve as a guiding document in the search for financing for low-cost housing and guide the work's execution and supervision. The objective is that these constructive proposals become generalized, and the Guadua angustifolia Kunth bamboo becomes a material with multiple applications to contribute to the housing problem in Ecuador.
\end{abstract}

Keywords: Construction industry, construction material, ecological footprint, Guadua angustifolia Kunth, low-cost housing, low-income housing, sustainable and sustainable habitat, vernacular architecture. 


\section{Introducción}

En conjunto con la problemática de crecimiento poblacional, el incremento en la necesidad de obtención de viviendas y el deterioro de nuestro entorno, el mundo está inmerso en la necesidad de medidas drásticas para la preservación del medio ambiente, el ahorro energético, el uso de materiales que contribuyan al desarrollo local y la disminución de costos de fabricación de viviendas. Las soluciones que se planteen deben mejorar la calidad de vida de los habitantes. Sin embargo, la industria de la construcción tiene un alto impacto ambiental al consumir una gran cantidad de recursos y contaminando el entorno (Sánchez, 2020).

Ha surgido una incompatibilidad en el modus vivendi del humano y lo natural, llevando a un desequilibrio entre el ser humano, el hábitat y la naturaleza. La mejora técnica de los materiales con los que se construye ha sido a costa de sus cualidades biológicas y de su inocuidad ambiental, y es aquí donde surge la bioconstrucción como acción respetuosa del medio ambiente y de la vida (Rubio, 2019).

A partir de los elementos señalados, nacen las propuestas de viviendas bioclimáticas que incorporan la mayor cantidad de elementos del medio ambiente y aprovechan al máximo los recursos naturales disponibles (sol, vegetación, lluvia, vientos), reduciendo así en un gran porcentaje el impacto ambiental dejado por las construcciones y disminuyendo la huella ecológica. Ejemplos de estas propuestas son las aportadas por Herrera \& Oyola (2020), donde se usaron materiales eficientes para módulos de viviendas sostenibles, se consideraron los factores bioclimáticos, el aprovechamiento de materiales de la zona, ventilación e iluminación natural, ventilación cruzada, entre otros. Otra propuesta que además integra propiedades sismo resistentes a las viviendas es la hecha por Trujillo, Nieto, Vanegas \& Díaz (2020), donde incorporan calidad a las viviendas de interés social.

Uno de los elementos a considerar para hacer que las edificaciones sean sostenibles es la caña guadúa por tener características físico químicas ideales para su uso en construcción, además de ser un tipo de biomasa de rápido crecimiento, gran adaptabilidad a diferentes terrenos demandando poco mantenimiento, y un mecanismo regenerativo de auto propagación que garantiza su suministro (Ardila, Folgueras, \& Fernández, 2020).

La caña guadúa tiene propiedades estructurales que la hacen resistente, flexible y con gran capacidad de absorber energía, lo que la convierte en un material ideal para construcciones sismo resistentes. Todas sus partes son aprovechables, posee fibras naturales muy fuertes lo que la hace digna de competir con la madera y útil para elaborar aglomerados, laminados, pisos, paneles y esteras, entre otros (Fernández, 2020).

Ecuador, ha recibido aportes de gran valor en materia de construcción con caña guadúa como lo fue después del terremoto de abril de 2016, que afectó a la costa ecuatoriana, donde arquitectos japoneses como Shigeru Ban y Hiroto Kobayashi mostraron el uso del material convencional para elaborar casas emergentes (Colegio de Arquitectos del Ecuador - Pichincha, 2017). También aportes de centros como la Universidad de Guayaquil, quienes en una de sus investigaciones afirman que además de sus bondades, representa parte importante de lo que es la identidad nacional de la vivienda tradicional y ancestral ecuatoriana (Poveda, Franco, Pilco, Suriaga, Rivera, \& Sacoto, 2016).

Como se aprecia, a pesar de que se han hecho avances en este sentido, existen múltiples elementos que han frenado la expansión de esta corriente de diseño bioclimático, asociados a limitantes como costos elevados en relación con la construcción convencional. No obstante, es muy temporal este 
criterio ya que ha ido cambiando en la medida en que se masifica la disponibilidad del material, la mano de obra calificada, la incursión de proyectos estatales con estas técnicas, e incentivos para el uso de materiales bioclimáticos, entre otras medidas.

Uno de los problemas que enfrentan quienes desean construir viviendas de este tipo de interés social a pesar de ser constructores empíricos, es el desconocimiento de regulaciones que encaminen los parámetros de construcción con este material, desconocimiento sobre diseño arquitectónico y bioconstrucción, no accesibilidad al tener costos máximos financiables para este tipo de vivienda y el desconocimiento sobre la forma de presentar el proyecto para que les sea aprobado. Adicionalmente, Garavito (2020) concluyó que la implementación de políticas que incluyan el uso de guadua es lenta y no efectiva, y tiene su origen en el desconocimiento del marco constitucional y legal relativo. Respecto al manejo de la caña, Melo y Valenzuela (2021) concluyen que es necesario que las comunidades conozcan y manejen la cadena productiva del bambú y también su uso sostenible, por lo que se requerirá de capacitaciones hacia esos sectores.

Es por ello que surge la necesidad de realizar esta investigación, cuyo objetivo es el de estudiar los aspectos más relevantes de la construcción con caña y preparar una memoria descriptiva que sirva de marco de referencia para su presentación y ejecución. Esta investigación puede ser consultada por los maestros constructores, ingenieros, arquitectos y los que de alguna manera se vean involucrados en la construcción de viviendas utilizando caña guadua como material de construcción principal; no pretende sustituir el trabajo de ingenieros civiles, arquitectos, técnicos, ni maestros de obras, aclarando que es recomendable hacer uso de los resultados planteados solo como guía referencial.

Dentro de los objetivos y alcance de los componentes de la memoria que se presenta, se indica que respondió a un requisito de certificación del curso sobre Construcción en Caña Guadúa del proyecto "Implementación de Escuela Taller para la reconstrucción de Manabí, financiado por la Agencia Española de Cooperación Internacional para el Desarrollo (AECID), el Gobierno Provincial de Manabí y Manabí Produce, en colaboración con la Universidad Laica Eloy Alfaro de Manabí y la Universidad Técnica de Manabí.

El proyecto en el que se basa la memoria presentada tiene como objetivo definir el diseño y cálculo presupuestario de una vivienda unifamiliar de interés social hecha principalmente con caña guadúa angustifolia, para ofrecer diseños alternativos de costos accesibles que incorporen parámetros de confort bajo el concepto de bioconstrucción.

La caña guadúa es una gramínea gigante, pertenece a la familia del bambú. A nivel mundial existen alrededor de 1500 especies, de las cuales aproximadamente 280 son nativas de la región. Es cultivada en regiones tropicales y subtropicales del Ecuador. Es uno de los materiales más versátiles y se ha usado de diversas maneras, principalmente en la construcción (Delgado, 2017, p. 82).

La propuesta, ha buscado el uso mínimo de presupuesto, materiales con baja huella de $\mathrm{CO}_{2}$, promover el uso de recursos sustentables, así como el consumo responsable de agua y la promoción del consumo y desarrollo local. También, se ha debido cumplir los requisitos expresados en el "Reglamento para el acceso a subsidios e incentivos del Programa de vivienda de interés social y público en el marco de la intervención emblemática Casa para todos" (Decreto Ejecutivo No 681, 2019), y en el "Reglamento para validación de tipologías y planes para proyectos de vivienda de interés social" (Ministerio de Desarrollo Urbano y Vivienda, 2019). 


\section{Metodología}

El tipo de investigación es aplicada, ya que los conocimientos adquiridos son puestos en práctica y resultan de provecho para la sociedad al hacer una propuesta arquitectónica. La propuesta se hace en base a una revisión bibliográfica que, según Campos (2017),

... utiliza textos (u otro tipo de material intelectual impreso o grabado) como fuentes primarias para obtener sus datos. No se trata solamente de una recopilación de datos contenidos en libros, sino que se centra, más bien, en la reflexión innovadora y crítica sobre determinados textos y los conceptos planteados en ellos. (p. 17)

Las fuentes mayormente consultadas fueron la norma NEC-SE-GUADÚA (Ministerio de Desarrollo Urbano y Vivienda, 2016), además de los libros y artículos científicos referentes a construcción ecológica, bioconstrucción y caña guadúa. Las búsquedas se realizaron con las siguientes palabras clave: arquitectura vernácula, bioconstrucción, guadúa angustifolia, memoria descriptiva, NEC-SEGUADÚA, guadúa Ecuador, construcciones en Ecuador con guadúa, entre otras, excluyéndose aquellas encontradas anteriores al año 2008.

El procedimiento de investigación se llevó a cabo mediante las siguientes tres fases:

\section{Fase 1 - Referentes teóricos}

El objetivo de esta fase es estudiar los aspectos más relevantes de la construcción con caña guadúa y se realizó a través de las siguientes actividades:

Asistencia al curso presencial ofrecido por la Escuela Taller y desarrollado en las instalaciones de la Universidad Técnica de Manabí en el auditorio de la Facultad de Ciencias Matemáticas, Físicas y Químicas.

Investigación de los referentes teóricos necesarios para el desarrollo de la propuesta.

Visita de campo a vivienda construida por el Ministerio de Desarrollo Urbano y Vivienda y a productores locales de caña guadúa.

\section{Fase 2 - Diseño del proyecto}

El objetivo de esta fase es desarrollar el anteproyecto y comprende las siguientes actividades:

Definición de las necesidades.

Determinación de los materiales y el sistema constructivo ideal en términos bioclimáticos y sostenibles para la propuesta de vivienda.

Planteamiento de un diseño que contemple mejoras a los ya existentes y que permita sentar las bases para nuevas investigaciones con el uso de caña guadúa en el diseño de viviendas unifamiliares.

Realización del presupuesto acorde al diseño planteado y a los requisitos establecidos por los organismos competentes.

\section{Fase 3 - Memoria descriptiva}

El objetivo de esta fase es desarrollar la memoria descriptiva. Esta ha de servir como documento guía para la presentación ante los organismos competentes en la búsqueda de financiamiento a bajos intereses para viviendas de interés social o subsidio total, y también como guía para la ejecución y 
supervisión de la obra. La meta es que estas propuestas constructivas se masifiquen y se conviertan en un material de múltiples aplicaciones para la solución del problema de la vivienda en el Ecuador.

A continuación, se presenta una figura que ilustra el procedimiento descrito (Figura 1).

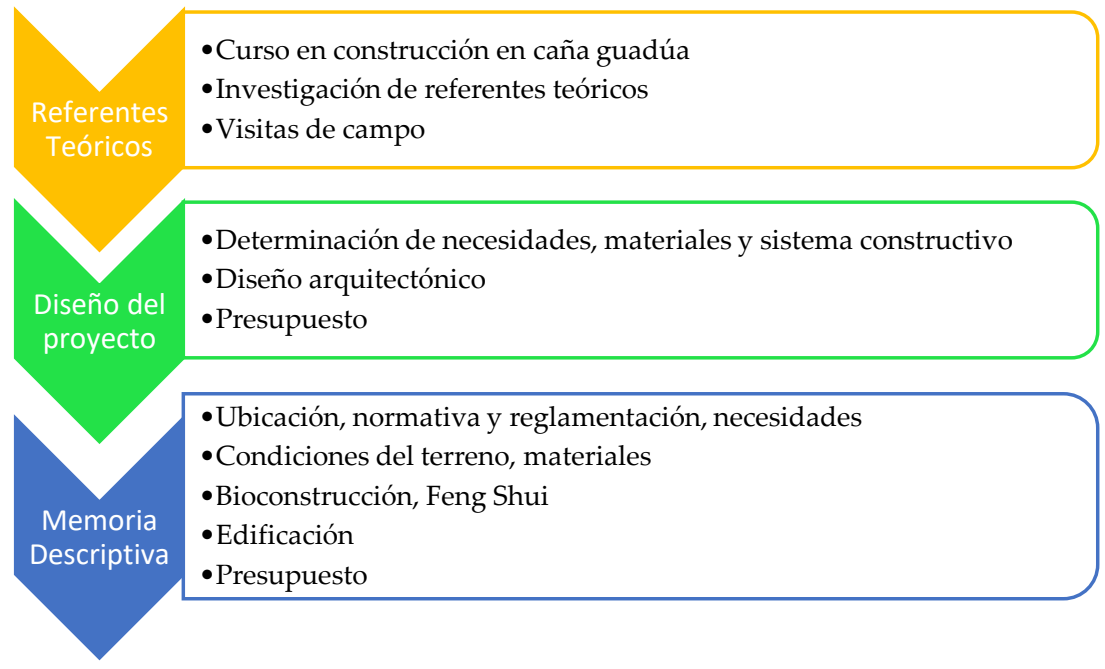

Figura 1: Metodología de trabajo y flujo de actividades.

\section{Resultados y Discusión}

A continuación, se presenta la memoria descriptiva resultado de la investigación.

\subsection{Ubicación}

La parcela donde se construya la vivienda debe cumplir con ciertos requisitos; para ello, existen procesos de calificación de terrenos en el Banco de Suelos, que es desarrollado por la Subsecretaría de Uso, Gestión de Suelo y Catastros del MIDUVI. Este proceso comprende el registro, la revisión y validación, la categorización, la inspección y la calificación. Dentro de la revisión y validación, el MIDUVI revisa que se cumplan mínimos requisitos de postulación, entre los que se encuentran (Ministerio de Desarrollo Urbano y Vivienda, 2018, p. 38):

c. No encontrarse en zona de riesgo no mitigable, área protegida o sitios patrimoniales arqueológicos.

d. Contar con disponibilidad o factibilidad de servicios, o que por sus características permita la implementación de sistemas alternativos para su dotación.

e. Encontrarse en zona urbana o rural de expansión urbana que esté consolidando el área amanzanada.

f. Informar sobre la calificación del uso y ocupación del suelo, el cual deberá ser compatible con la implementación de viviendas.

Es de vital importancia que la ubicación esté libre de posibles amenazas como lo son el construir en zonas de alto riesgo sísmico, inundaciones, amenaza por actividad volcánica y deslizamientos. Debe tener fácil acceso a la parcela, estar cerca de vías de acceso vehicular, y en lo posible, de fácil acceso al transporte público. Además, deberá contar con acceso a la red de servicios públicos y con los 
permisos requeridos para este tipo de proyecto como los establecidos en las ordenanzas que regulan y controlan las edificaciones y construcciones a nivel cantonal.

A este respecto Morán (2015) menciona que, uno de los aspectos importantes para una edificación segura a tomar en cuenta es el terreno, indicando que deben estar alejados de las quebradas o ríos para evitar las crecientes de agua, evitar las pendientes pronunciadas en donde pueda haber deslizamientos, y no ubicar las viviendas en suelos inestables, rellenos o propicios a la licuación.

\subsection{Normativa y reglamentación aplicada}

Las normas a considerar para este tipo de construcción y del manejo de la caña guadúa son de corte internacional y nacional. Entre las foráneas tenemos las relacionadas con cantidades y unidades, las referentes al acero, construcción sismo resistente, sismicidad en estructuras de madera, manejo de la caña guadúa, estructuras con guadúa, métodos y ensayos, normalización y certificación. Por nombrar algunas tenemos las American Concrete Institute (ACI, Estados Unidos), la ISO TC165 N-313 (Bamboo Estructural Design, Canadá), la NTC 5407 (Norma Técnica Colombiana), Norma E.100 Bambú (Lineamientos Técnicos para el diseño y construcción de edificaciones sismorresistentes con bambú en el Perú), entre otras.

En cuanto a la normativa de Ecuador en especial, es la relacionada al Código NEC-SE-GUADÚA (Ministerio de Desarrollo Urbano y Vivienda, 2016), y a las normas de la construcción:

NEC-SE-CG: Cargas (no sísmicas).

NEC-SE-DS: Peligro sísmico y requisitos de diseño sismo resistente.

NEC-SE-RE: Riesgo sísmico, evaluación, y rehabilitación de estructuras.

NEC-SE-GC: Geotecnia y diseño de cimentaciones.

NEC-SE-HM: Estructuras de hormigón armado.

NEC-SE-AC: Estructuras de acero.

NEC-SE-MP: Estructuras de mampostería estructural.

NEC-SE-MD: Estructuras de madera.

NEC-SE-VIVIENDA: Viviendas de hasta 2 pisos con luces de hasta $5 \mathrm{~m}$.

NEC-DR-BE: Viviendas de bahareque encementado de uno y dos pisos.

\subsection{Descripción de las necesidades}

Se partirá de la premisa de que una vivienda bioclimática es favorecedora de una relación armónica entre los ocupantes, el hábitat y el medio; se realiza para ser adaptada al clima en todos sus aspectos (temperatura, soleamiento, régimen de lluvias y vientos dominantes), con la finalidad de conseguir un ambiente confortable durante todo el año, tanto en los ambientes interiores como exteriores. Ferro (2015) reportó que las viviendas bioclimáticas no dañan al medio y son saludables y sus objetivos son la optimización de los recursos naturales y apuestan por la arquitectura sostenible.

La vivienda debe contar con acceso a personas de necesidades especiales que usen sillas de rueda, lo que implica que una de las habitaciones deberá poder tener acceso a ella según la normativa, al igual que el baño y los pasillos de la casa. Hay que tomar en cuenta esta exigencia también a la hora de la colocación de accesorios y alturas acordes, así como los accesos tanto a la vivienda como a las diferentes áreas del baño. 
El presupuesto deberá ser menor o igual a $16.448 \$$, que debe cubrir todo el proceso de construcción como los gastos preliminares de replanteo, excavación y demás, la estructura de hormigón, la estructura armada en caña guadúa, la mampostería, cubierta, acabados, las instalaciones eléctricas, la mano de obra y el transporte. Otro requisito es contar con tres dormitorios y que el área total sea de al menos $57 \mathrm{~m}^{2}$.

Según el Reglamento para el acceso a subsidios e incentivos del programa de vivienda de interés social y público en el marco de la intervención emblemática "Casa para todos", las viviendas de interés social son “... la primera y única vivienda digna y adecuada, en áreas urbanas y rurales, destinada a los ciudadanos ecuatorianos en situación de pobreza y vulnerabilidad" (Decreto Ejecutivo No 681, 2019). Así mismo, indica que estas viviendas de interés social deben ser ajustadas a segmentos como el primero, que corresponden a una "... vivienda de interés social con subsidio total del Estado (100\% de subsidio), para beneficiarios que cumplan los criterios de elegibilidad y priorización (pobreza y vulnerabilidad) determinados por el ente rector de desarrollo urbano y vivienda..." (ibid.).

Las disposiciones presupuestarias responden a lo expresado en el Reglamento para validación de tipologías y planes para proyectos de vivienda de interés social (Ministerio de Desarrollo Urbano y Vivienda, 2019), en su artículo 3 (referente a la segmentación de las viviendas de interés social, el acceso a los subsidios e incentivos del Programa de Vivienda de Interés Social y Público Casa para Todos), en la sección 3.1 (correspondiente al primer segmento con subsidio total), establece:

3.1.2 Unifamiliar en Terreno Propio del beneficiario tres dormitorios (41.12 SBU). - Vivienda de tres dormitorios en un área habitable mínima de $57 \mathrm{~m}^{2}$, entendida por una solución habitacional, vivienda aislada o adosada, la misma que será construida en el terreno de propiedad del beneficiario. Cuyo diseño prevé la disposición de espacios para tres dormitorios, sala, comedor, cocina, cuarto de baño y área de lavado y secado con tendedero de ropa. (Ministerio de Desarrollo Urbano y Vivienda, 2019, p. 5)

El Decreto No 681 (2019) estableció el subsidio total del estado para viviendas de interés social construidas en terrenos propios del beneficiario en 41.12 SBU (Salario Básico Unificado). Según acuerdo ministerial, queda establecido en $400 \$$ mensuales el SBU a partir del 01 de enero de 2021 (Ministerio del Trabajo, 2020). Esto implica que se tendrá disponible para la construcción de la vivienda hasta $16.448 \$$.

Dentro de los requisitos de diseño ampliado y demás conceptos importantes a la hora de construcción, los empalmes deben resistir los esfuerzos producidos por las combinaciones de carga, su sistema estructural debe ser sismo resistente, verificar las cargas actuantes sobre la estructura, tomar en cuenta las condiciones ambientales, contemplar los principios de mecánica estructural, contemplar la capacidad de disipación de energía, usar el diseño por método de esfuerzos admisibles. Es importante regirse por las normas de diseño de elementos sometidos a flexión, diseño de elementos solicitados por fuerza axial y por flexión y carga axial combinadas, requisitos de resistencia y rigidez, diseño de uniones, garantía de la protección de la estructura a factores ambientales, garantía de adecuada ventilación, sellado de las aberturas en el armado estructural, entre otros. Autores como Morán (2015) indican, por ejemplo, que se deben colocar las cargas sobre los nudos, o también se puede rellenar la caña de concreto, debe haber la presencia de un nudo en cada extremidad para evitar fisuras, las cimentaciones deben ser calculadas en base a las cargas, la estructura portante debe soportar todo el peso ya que de eso depende la estabilidad de la edificación 
(peso de los muros, techos, personas, mobiliario, carga de sismos, cargas de eventos, choques, impactos).

Para el material principal de construcción, que es la caña guadúa, deberá planificarse su preservación con amplios aleros para la protección del sol y un sobrecimiento de mínimo $200 \mathrm{~mm}$ para evitar la humedad; además, tener en cuenta trabajar en base a un diseño moderno y diferente de vivienda, combinado con mejoras relacionadas a aspectos climáticos, ergonómicos, acabado de terminación fina, entre otros, lo que significará un extra a los diseños tradicionales de las viviendas de interés social.

\subsection{Condiciones del Terreno}

Los terrenos en donde se construya la vivienda o el conjunto de viviendas deben contar con estudios geotécnicos y derivado de ello revisar el dimensionamiento de la estructura. El tipo de suelo será determinante para tener cimentaciones adecuadas, aunque se sabe que éstas también dependen del tipo de edificación. También deberá contar con estudios de mecánica de suelos para analizar la incidencia de las cargas a la superficie. López (2015) reporta que debe realizarse un estudio geotécnico que cumpla los requisitos de la norma de estudios geotécnicos del país, en los siguientes casos: (a) Suelos que presenten inestabilidad lateral. (b) Suelos con pendientes superiores al 30\%. (c) Suelos con compresibilidad excesiva. (d) Suelos con expansibilidad de intermedia a alta. (e) Suelos que presenten colapsibilidad. (f) Suelos en zonas que presenten procesos de remoción en masa, áreas de actividad minera activa, en recuperación o suspendida, erosión, cuerpos de aguas u otros que puedan afectar la estabilidad y funcionalidad de las casas.

Debe evitarse que posterior a la construcción se creen grietas por asientos diferenciales. Previo al estudio, deben conocerse datos como el perfil del terreno, servicios enterrados, si se han hecho vertidos en el mismo, y si está sobre una falla, un relleno o galería.

Se sugiere que, en el perímetro de la vivienda, se siembren gramíneas o cualquier tipo de vegetación de pequeña altura que ayuden a disminuir el efecto de la radiación solar (albedo) que incida directamente sobre la cubierta exterior y por ende llegue a generar un efecto nocivo en la estructura de la caña guadúa, así como también en el enlucido, puertas y ventanas de madera.

\section{5. $\quad$ Condiciones de los materiales}

Evitar a toda costa el uso de materiales de baja calidad para garantizar las condiciones de seguridad de la vivienda y también de la salud de sus habitantes, en especial, en cuanto al uso de la caña guadúa para la parte estructural.

Prestar especial atención a que la selección de culmos sea la idónea. Los culmos, son el "Tallo del bambú, formados por nudos y entrenudos que emergen del rizoma, son el equivalente al tallo de un árbol" (Ministerio de Desarrollo Urbano y Vivienda, 2016). Debe cuidarse que no tengan daño en su estructura, que hayan sido correctamente preservados y secados, que la humedad sea la acorde al lugar de construcción, que no tengan deformaciones, que su porcentaje de conicidad sea el adecuado; también se debe verificar si tiene grietas, que estén sin perforaciones, libre de enfermedades. Los culmos estructurales son de especial interés ya que no pueden presentar arrugas perimetrales debido a fallas de compresión en el crecimiento de la caña guadúa. Yann (2020) reporta que en zonas rurales se tiende a emplear caña de baja calidad y sin tratamiento por economizar, estando sujeto el material a múltiples fallas y sin durabilidad; esto resulta en una imagen en general 
de baja calidad asociada a la pobreza, impidiendo ser considerado como alternativa constructiva creíble. Para el resto de los materiales, se recomienda verificar su procedencia, es decir, si estos son reciclados constatar su vida útil y condiciones. En cuanto a la estructura de hormigón armado, debe comprobarse su calidad, composición y resistencia; para la malla electrosoldada, es importante cuidar las soldaduras y la calidad de las viguetas.

\subsection{Bioconstrucción}

Rubio (2019) reportó que el término bioconstrucción aparece a raíz de la necesidad de buscar alternativas constructivas equilibradas entre el hábitat y el ser humano. Propone además que el manejo de los recursos naturales, de las cualidades del entorno y de los materiales, se haga de manera consciente, así como los condicionamientos (físicos y sociales) y las tecnologías no contaminantes. Esto lleva al fomento de una arquitectura bioclimática, basada en el esquema de la sustentabilidad, donde se busca el equilibrio entre el medio ambiente, el hombre y la economía, y cuyos objetivos son la armonización de espacios con óptimas condiciones de confort y bienestar de sus integrantes, el hacer un uso eficiente de los recursos y las energías, y la aplicación de un diseño bioclimático.

Es menester que los individuos se adapten a sus entornos de manera natural como lo ha hecho por décadas la arquitectura vernácula, en la que sus comunidades han construido su propio hábitat en forma continua, siendo este testimonio de la cultura popular, construyendo en base a conocimientos empíricos transferidos de generación en generación y respondiendo al clima y a los materiales del entorno (Espejo, 2015). En este sentido, Chiriboga (2018) reporta que “La arquitectura vernácula y el uso de materiales alternos a los habituales han demostrado que puede generar soluciones funcionales y confortables de vivienda." A propósito de lo citado anteriormente en relación con la búsqueda de alternativas, de equilibrio entre el hábitat, el hombre y sus actividades, la sustentabilidad, uso de materiales de la zona y tomando como referencia la arquitectura vernácula manabita, Rivadeneira (2017) reporta que Portoviejo capital de la Provincia de Manabí, se encuentra situado en el centro de la costa ecuatoriana. La ciudad se encuentra atravesada por el Río Portoviejo, la historia nos narra que el río era el principal canal comercial de la ciudad, esta particularidad ha provocado que desde los primeros asentamientos se utilicen los recursos que brinda el hábitat; la Caña Guadúa es uno de esos recursos.

De igual manera, se sabe que el edificar causa un gran impacto en el medio ambiente, y la bioconstrucción pretende minimizarlo, ayudando a un desarrollo sostenible, que no agote los recursos, entendiéndose como la forma de construir respetuosa con todos los seres vivos. Para ello se debe tener en consideración la gestión del suelo, del agua, el aire, la energía y el consumo y desarrollo local. En el proyecto presentado no se analiza la gestión del suelo, sin embargo, en cuanto al agua, se promueve su uso y aprovechamiento responsable. A pesar de que las lluvias en Manabí caen generalmente en el denominado invierno, es necesario concientizar a la ciudadanía sobre la importancia de este vital recurso. Una forma de hacerlo es colocando canaletas para la recolección de aguas lluvia, aprovechando la inclinación de los techos y su material para facilitar así su recolección. Esta agua puede ser reutilizada (a pesar de no ser potable) para el inodoro, limpieza, jardín, lavadora, cultivos. Los beneficios del uso de agua de lluvia son el hecho de que es gratuita, es natural (sin cloro y sin cal), es directa de la naturaleza; al no ser agua dura se ahorra en detergente y suavizante, es el mejor alimento para las plantas, se contribuye al ahorro de las reservas de los ríos y lagos, y se promueve la sostenibilidad. 
Es importante aclarar, que el agua dura es aquella que contiene niveles de minerales altos, en especial de calcio y magnesio (Quispe, 2016). Por otro lado, el agua blanda contiene la mínima concentración de lo que es carbonato de calcio y otros, pudiendo generar espuma fácilmente (Molina, 2019). El agua de lluvia es agua destilada por las nubes y el sol, considerada un agua muy blanda (Cortes, Hernández, Guerrero, \& Vega, 2011). La gestión del aire se promueve con el diseño de la ventilación cruzada, término de la arquitectura bioclimática que promueve el aprovechamiento del viento como recurso natural, gratuito, renovable y saludable, dando confort térmico a la vivienda. Con esto se aporta en la disminución del consumo de energía, seleccionando ésta en vez del aire acondicionado. La ventilación cruzada es la inducción del viento en los espacios interiores dependiendo del ángulo de incidencia del flujo y del diseño de las aberturas (Escudero, 2018). La ventilación cruzada natural usada en el diseño de la vivienda propuesta, se da cuando las aberturas del recinto se disponen en paredes opuestas o adyacentes, permitiendo la circulación, entrada y salida del aire, renovando el aire y bajando la temperatura. Además, se han diseñado aleros prominentes para proteger la vivienda del sol y a la caña.

Otra consideración importante es la ventilación natural inducida, donde se considera que el “...movimiento natural del aire (no forzado por elementos mecánicos) puede ser inducido por una serie de efectos físicos que aprovechan las diferencias de temperatura del aire, de presión entre el exterior y el interior..." (García, García, \& Saraví, 2015). Se ha incluido la inducción térmica utilizada para llevar a cabo la refrigeración por aire en el diseño. El aire caliente se desplaza hacia arriba al perder peso y su lugar es ocupado por el aire con menor temperatura. Así, el aire caliente sale por las aberturas que están dispuestas de manera especial en el techo, reduciendo así el uso de energía por ventilación artificial. Para contribuir con la gestión de energía, siguiendo los principios de la bioconstrucción, el hecho del aprovechamiento de agua de lluvia y el uso de ventilación natural ya aporta a este elemento. Pero otro aporte de gran relevancia es lo relacionado a las emisiones de $\mathrm{CO}_{2}$. Vázquez \& Guillén (2016) reportaron que la industria de la construcción incluida su industria asociada, es la responsable del consumo de más del $40 \%$ de recursos naturales, de un 30\% de energía y el 30\% de las emisiones de gases de efecto invernadero. Estos autores también reportan que, en lo referente al dispendio de recursos, la construcción de edificios consume el 40\% de roca, arena y gravilla, además del $25 \%$ de madera no renovable y $16 \%$ del agua utilizada anualmente en el mundo. Britez, Pacheco, Levy, \& Helene (2015) reportaron que el cemento producido en todo el mundo corresponde entre $5 \%$ y $8 \%$ del total global de $\mathrm{CO}_{2}$ emitido anualmente a la atmósfera. Britez et al. (2015) también reportaron que cada tonelada de cemento en su fabricación, emite 1 tonelada de $\mathrm{CO}_{2}$ a la atmósfera. Esto, en contraste con investigaciones realizadas para el cálculo de emisiones de la caña guadúa, se obtiene un índice de “... 0,225 kg de $\mathrm{CO}_{2}$ por cada kilogramo de material puesto en obra..." (EcoHabitar, 2020).

En cuanto al consumo, Muñoz \& Quiroz (2014) reportan que para producir un metro cúbico de hormigón premezclado se requieren 342 MJ. Otros autores como Moran (2011) comparan la tasa de energía requerida para la producción de un metro cubico de diversos materiales de construcción (Tabla1).

Tabla 1: Tasa de energía para la producción de materiales de construcción (Eco - Costo).

\begin{tabular}{llr}
\multicolumn{1}{c}{ Material } & \multicolumn{1}{c}{ Unidad } & Valor \\
\hline Hormigón & $\mathrm{MJ} / \mathrm{m}^{3}$ por $\mathrm{N} / \mathrm{mm}^{2}$ & 240 \\
Acero & $\mathrm{MJ} / \mathrm{m}^{3}$ por $\mathrm{N} / \mathrm{mm}^{2}$ & 1500 \\
Madera & $\mathrm{MJ} / \mathrm{m}^{3}$ por $\mathrm{N} / \mathrm{mm}^{2}$ & 80 \\
Bambú & $\mathrm{MJ} / \mathrm{m}^{3}$ por $\mathrm{N} / \mathrm{mm}^{2}$ & 30 \\
\hline
\end{tabular}


Referente a la acumulación de energía por tensión (de la máxima capacidad de acumulación dependerá su fortaleza y seguridad), tenemos en la tabla 2 una comparativa (Rodríguez \& Morales 2008):

Tabla 2: Energía de tensión acumulada (ETA).

\begin{tabular}{lrrr}
\hline \multicolumn{1}{c}{ Material } & \multicolumn{1}{c}{ Esfuerzo } & \multicolumn{2}{c}{ Eta } \\
\hline Hormigón & $\left(\mathrm{N} / \mathrm{mm}^{2}\right)$ & $\left(\mathrm{J} / \mathrm{m}^{3}\right)$ & $(\mathrm{J} / \mathrm{kg})$ \\
Acero & 8 & 1.200 & 0,5 \\
Madera & 160 & 64.000 & 8,2 \\
Bambú & 7,5 & 2.600 & 4,3 \\
\hline
\end{tabular}

Para cumplir con el parámetro de la bioconstrucción referente al desarrollo local, tenemos que el $66.5 \%$ del bambú de Ecuador es encontrado en la costa ecuatoriana y de ese porcentaje, la provincia de Manabí es la que cuenta con el mayor, ascendiendo a un total de 24.3\% (Ministerio de Agricultura y Ganadería 2018). Si se promueve el uso de la caña, se está incentivando a los productores a que mantengan activas sus manchas y estimulando a otros tenedores de tierra el cultivo de la misma.

\subsection{Otras consideraciones: El Feng Shui}

Para mejorar las condiciones ambientales que fomenten el bienestar y la armonía de los individuos que habitan la vivienda, se han incluido algunos principios del denominado Feng Shui, antiguo sistema filosófico chino de origen taoísta que se basa en la ocupación consciente y armónica del espacio con el fin de lograr de éste una influencia positiva sobre las personas que lo ocupan. Los principios básicos del Feng Shui son defender las ideas del hombre y la naturaleza en armonía, entre el espacio de edificación del hombre y su entorno natural (Yang, 2012). En este sentido y tomando en cuenta las recomendaciones de este sistema, se recomienda para los dormitorios evitar aparatos que emitan ruido y ondas como la TV, las computadoras, fax, entre otros, así como elementos que alteren el ánimo como papeles de trabajo. Es recomendable que la cama tenga un cabecero (para dar estabilidad y seguridad ante la vida) y que sobre esta no haya corrientes de aire. La cama debe tener acceso por ambos lados. Se recomienda que esté pintado con colores suaves y pasteles, en especial el celeste, ya que el azul es considerado un color pacífico, etéreo y espiritual; también usar verde para crear sensación de relajamiento y frescura. La cama, no debe estar ubicada justo enfrente de la puerta o bajo la ventana (esto puede mitigarse con cortinas). El dormitorio debe promover el buen descanso y el despertar con vitalidad.

Para el baño, se recomiendan colores como el verde, marrón, amarillo, naranja, rojo; sin embargo, el baño también puede ser considerado como una zona de relajamiento, por lo que podría usarse también el azul y verde. Los mobiliarios a colocar se recomiendan de madera y es de suma importancia que no existan botes de agua. También, que la tapa del inodoro esté siempre cerrada. La cocina no debe ubicarse frente al baño, y los elementos de fuego como el fogón y agua (lavaplatos), deben estar separados, o en su defecto, colocar objetos o divisiones entre ellos de acero o madera. Los colores deben ser neutros como el blanco, beige o tierra (no usar colores fríos ni cálidos). Al estar presente el fuego y el agua, se deben evitar colores como el azul y el rojo. En cuanto al comedor, éste debe estar próximo a la cocina. Para los accesorios, se debe usar metal y madera. Se recomienda una mesa ovalada con luz arriba de ella y un espejo que refleje la mesa para promover la prosperidad. Los colores recomendados son los cálidos, deben incitar a la socialización y al apetito, debiéndose evitar colores fuertes. 
La sala por otro lado, debe tener un sofá o silla que vea hacia la entrada. Los colores indicados son los mismos que para el comedor. Debe contener plantas y crear un centro de gravedad que puede ser algún objeto colocado en la mesa central del juego de sala. También pueden usarse los colores fuego. La sala es el corazón del hogar; se recomienda que la disposición de las sillas o muebles tengan presente que las personas puedan verse a la hora de conversar. Es importante a abrirse a conceptos no tradicionales para culturas latinas como este arte milenario. Orengo (2019) reporta que el Feng Shui se ha utilizado como guía para la arquitectura tanto en el ámbito de la edificación como de la ordenación urbanística desde tiempos inmemoriales, buscando la sostenibilidad, la integración en el medio ambiente y el bienestar del usuario.

\subsection{Edificación}

\section{Cimentación}

Los culmos no deben estar enterrados o inmersos en la cimentación o en cualquier otro componente directamente. Una vez que se lleve a cabo el trazado y las excavaciones, se deben ejecutar estas labores acordes al sistema constructivo a usar, apoyados en los planos estructurales y en los detalles constructivos.

Los cimientos serán de hormigón ciclópeo, añadiendo piedras y debiendo cuidar llenar bien los intersticios entre las rocas. Las propiedades de este tipo de hormigón permiten economizar material al aumentar el volumen de la mezcla, ser usado en terrenos de compactación pobre, mayor resistencia mecánica y química, entre otros. Gahona \& Montenegro (2016) recomiendan que la cama de hormigón deberá ser de aproximadamente $40 \mathrm{~cm}$ y estar conformado por un $40 \%$ de piedra y un $60 \%$ de hormigón aproximadamente. Se debe construir un sobrecimiento de $200 \mathrm{~mm}$ sobre el nivel del terreno, de forma que reciban los elementos estructurales de manera vertical de la caña guadúa (muros estructurales o columnas).

\section{Estructura}

La mayoría de las normas mencionadas en este documento guardan relación con la seguridad estructural de la edificación. La normativa NEC-SE-GUADÚA (Ministerio de Desarrollo Urbano y Vivienda, 2016) establece que, para los proyectos con las características del acá presentado, no requieren diseño estructural al no ser una planta con luces mayores a $3 \mathrm{~m}$, es inferior a $200 \mathrm{~m}^{2}$, no va a ser replicado en más de 15 unidades y no posee más de $3000 \mathrm{~m}^{2}$ de área construida.

A pesar de lo mencionado, para Trujillo et al., (2020), un diseño estructural usando un software de modelado que se base en elementos finitos, con simulación de comportamientos estructurales, permitirán verificar la capacidad del bambú como remplazo de los materiales convencionales de construcción. En Colombia, el diseño estructural de viviendas de interés social tiene la función de lograr la construcción de una edificación estable donde las cargas propias y de servicio y ante movimientos sísmicos den protección y salven las vidas, el patrimonio y los bienes de quienes las habitan (Trujillo et al., 2020).

Describiendo brevemente la estructura, se puede indicar que la vivienda está diseñada con una cimentación de zapata corrida de hormigón armado de $30 \times 30 \mathrm{~cm}$, integrada a una losa maciza reforzada con una malla electrosoldada, formando el contrapiso de la vivienda; los dos elementos en mención, se fundirán al mismo tiempo. La cubierta será de planchas de galvalume recubiertas de guadua, lo que mejora la resistencia térmica y acústica, colocada sobre una estructura con perfilería 
de acero con tubos cuadrados de $\mathrm{e}=2 \mathrm{~mm}$, anclada mediante tornillos autoroscantes de acero inoxidable de 5" con arandela.

\section{Planos arquitectónicos}

A continuación, se muestran la planta arquitectónica, las secciones S01 y S02, las fachadas frontal y lateral, y la planta de cubiertas en las figuras 2, 3, 4, 5, 6 y 7 respectivamente.

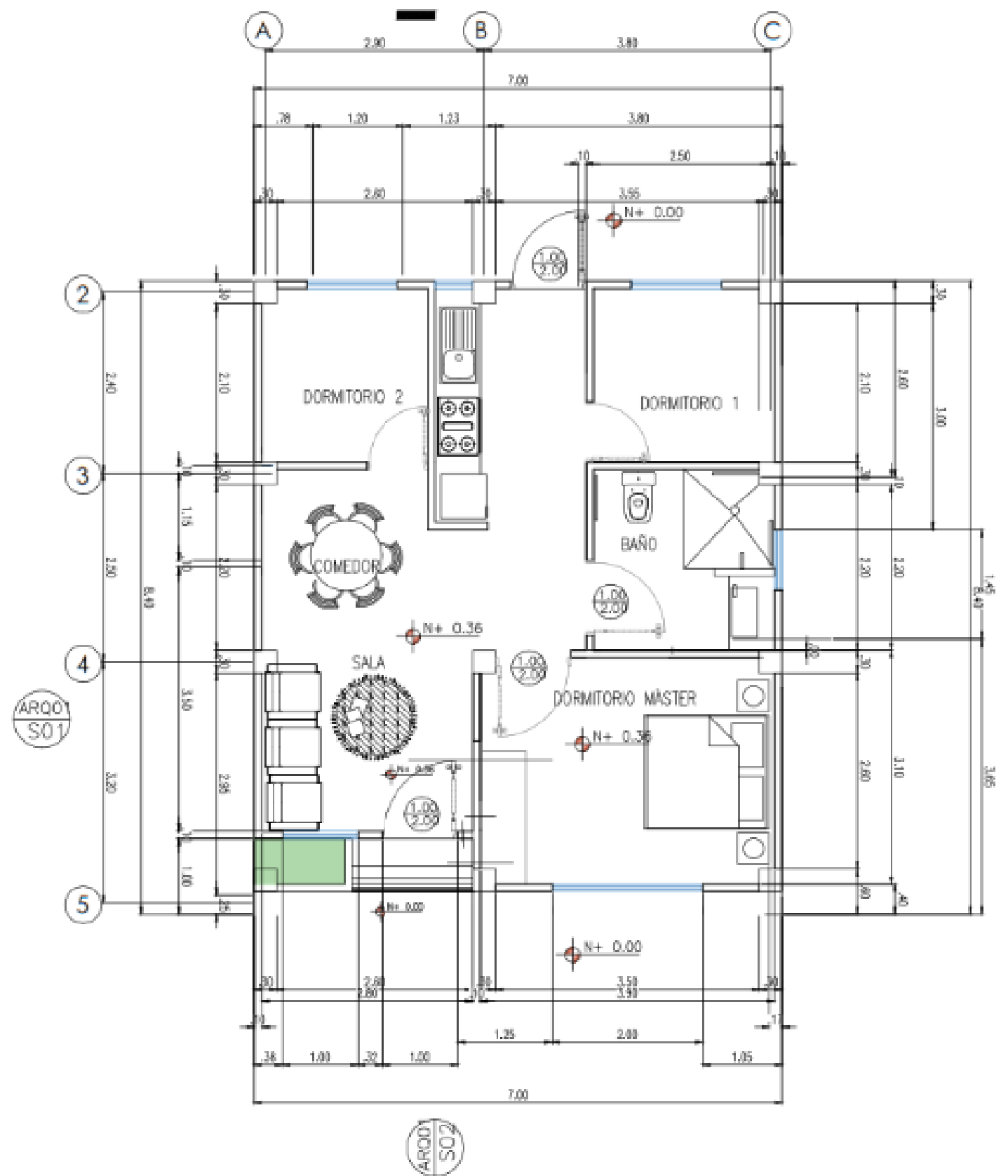

Figura 2: Planta arquitectónica de la propuesta. 
(A) 290 380

(C)

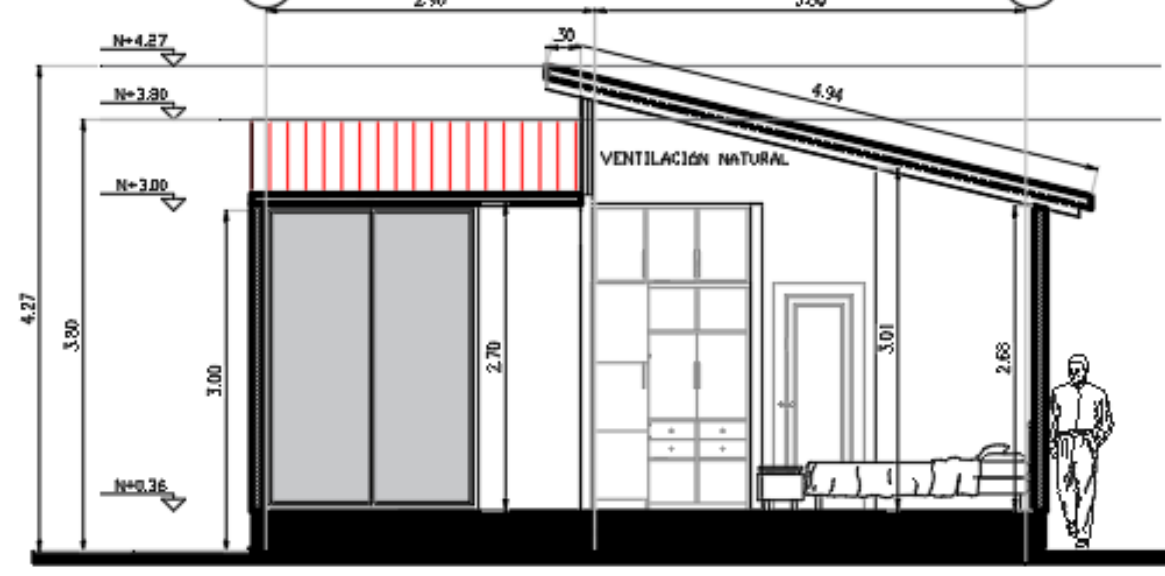

Figura 3: Sección S01.

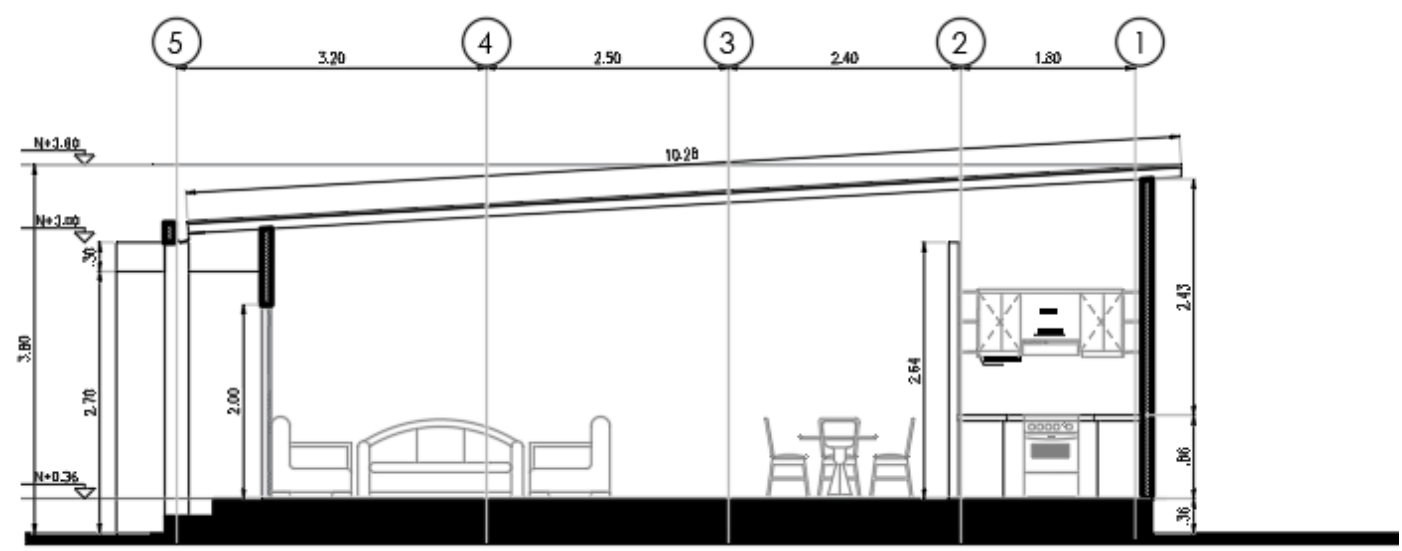

Figura 4: Sección S02.

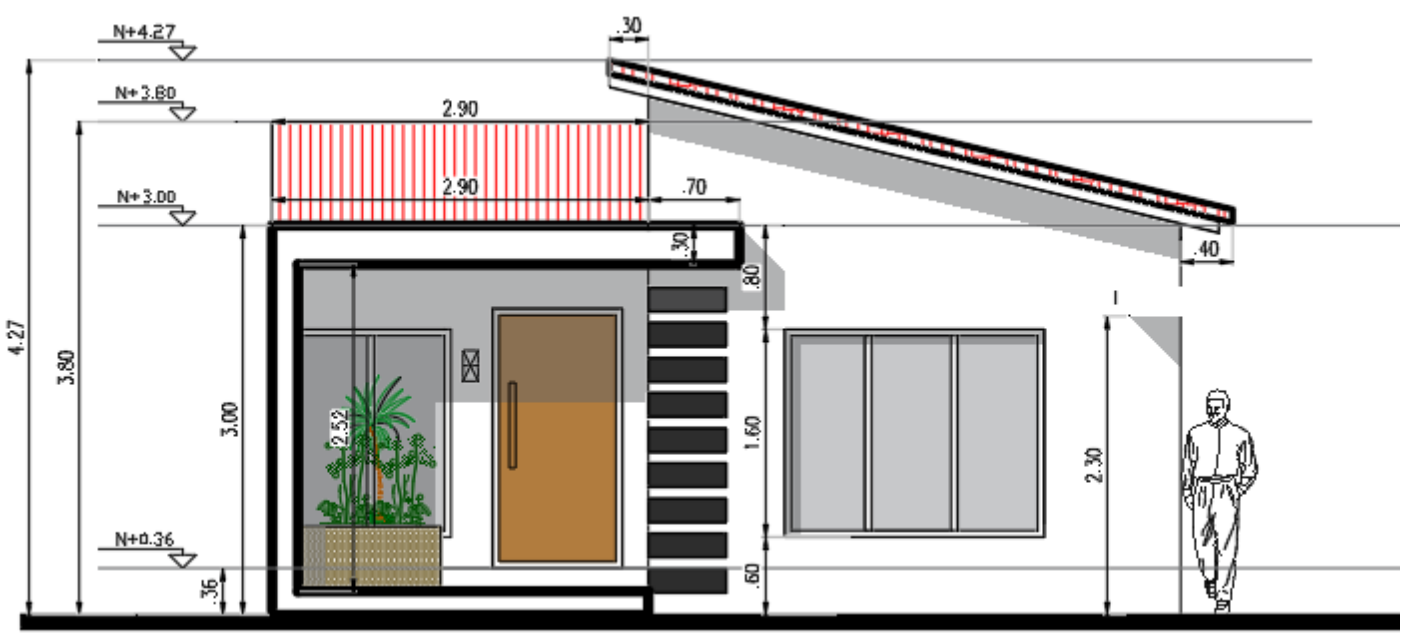

Figura 5: Fachada frontal. 


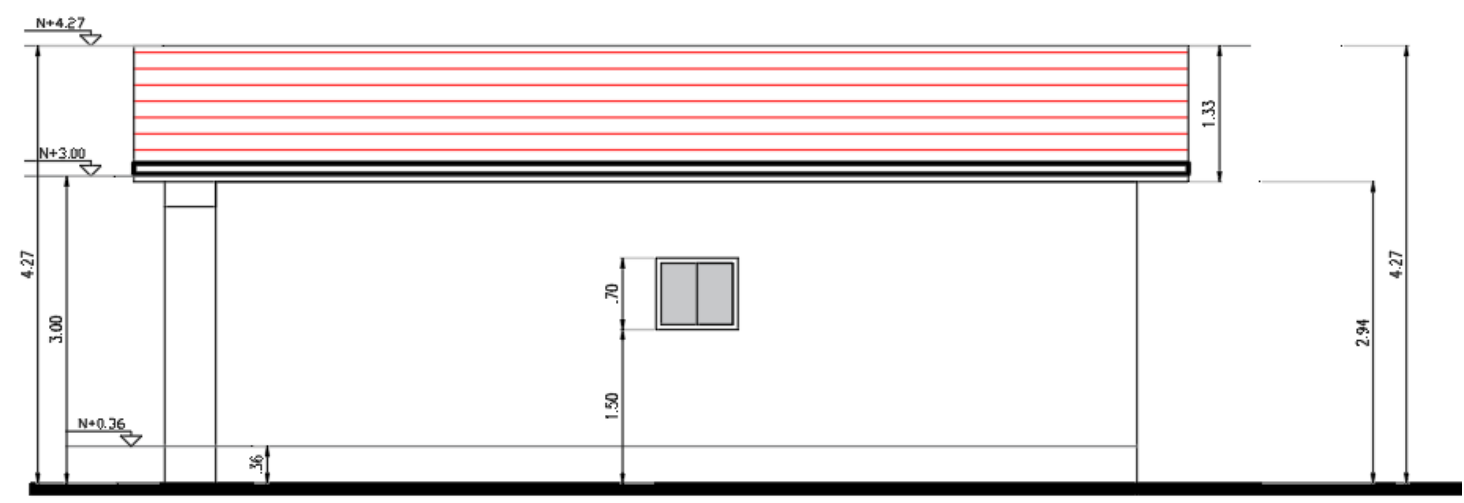

Figura 6: Fachada lateral.

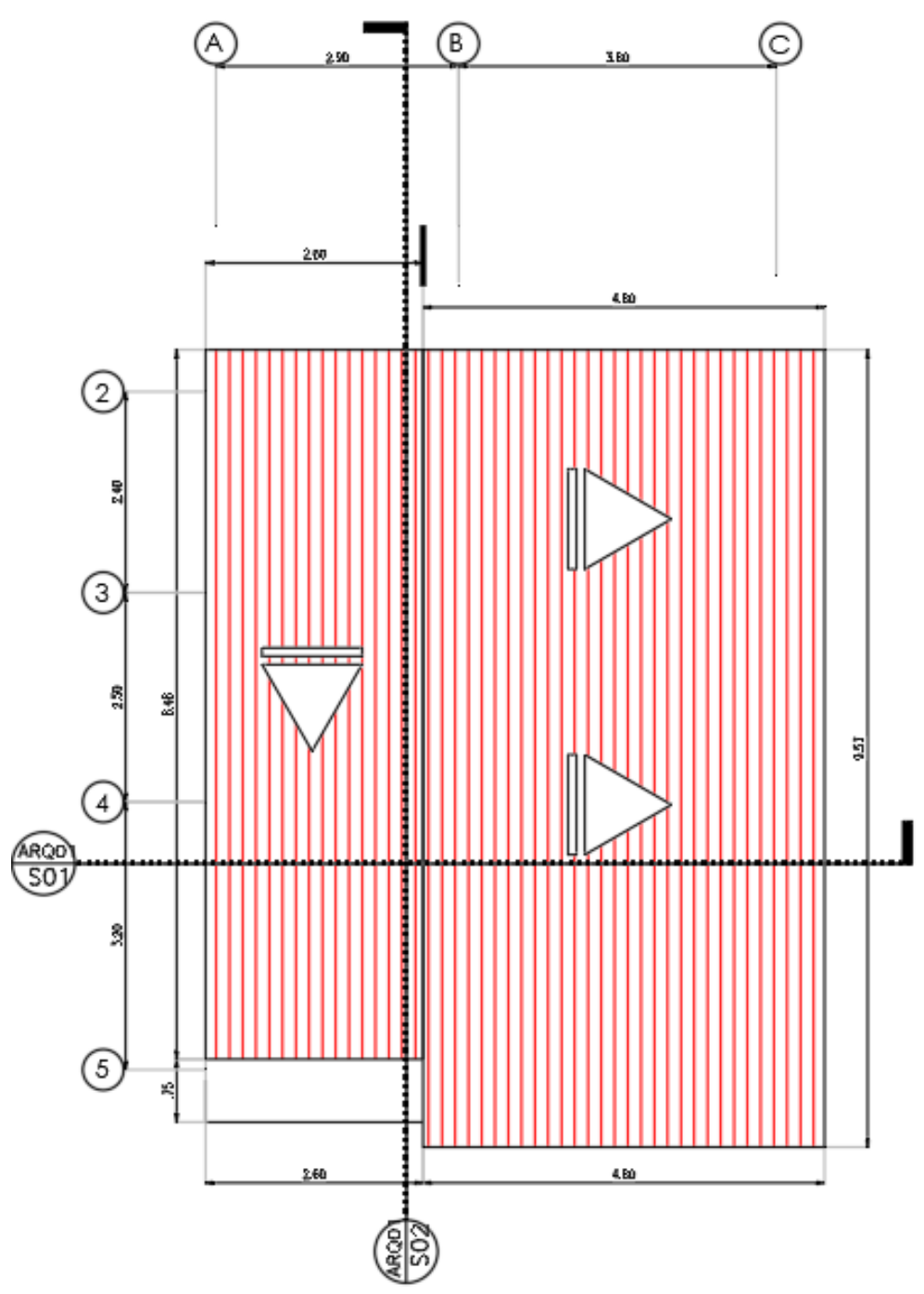

Figura 7: Planta de cubiertas.

\subsection{Presupuesto}

El presupuesto calculado para la construcción de la vivienda incluye las actividades preliminares, la estructura de hormigón armado, la estructura armada en caña guadúa, 
mampostería, cubierta, acabados e instalaciones eléctricas. En la tabla 3 se presentan los rubros principales.

Tabla 3: Presupuesto.

\begin{tabular}{lr}
\hline \multicolumn{1}{c}{ Descripción } & \multicolumn{1}{c}{ Costo, $\$$} \\
\hline Actividades preliminaries & 587.52 \\
Estruc. Hormigón armado & 2247.30 \\
Estruc. Arm. Caña guadúa & 3934.22 \\
Manpostería & 2856.71 \\
Cubierta & 1078.41 \\
Acabados & 2679.24 \\
Instal. Agua pot. y sanit. & 773.12 \\
Instalaciones eléctricas & 529.19 \\
Subtotal & 14685.71 \\
IVA & 1762.71 \\
Total & 16448.00 \\
\hline
\end{tabular}

Recapitulando los puntos principales expuestos, se considera que el problema de vivienda en Ecuador debe encaminarse no solo a suplir déficit de estas sino también debe contribuir a mejorar la calidad de vida y procurar el manejo sustentable de insumos de construcción. Para ello, se promueve el uso de la caña guadúa como material sostenible de construcción, acatando las normativas establecidas por el país y ajustándose a los requerimientos de los organismos competentes para hacer uso del subsidio del $100 \%$ de la construcción de la vivienda por parte del estado.

Para lograr esta propuesta, se ha hecho una investigación aplicada basada en una búsqueda bibliográfica, se ha tenido acceso a un curso de construcción con caña guadúa que, junto a la experiencia de los autores, permitió realizar el producto, que es la memoria descriptiva que posibilita a los lectores hacer uso de ella como guía, sin pretender sustituir las directrices dadas por el ingeniero civil a cargo de la obra y el arquitecto responsable de diseño.

\section{Conclusiones}

El crecimiento poblacional junto al aumento de la demanda de vivienda hace que la arquitectura y construcción tengan un alto impacto ambiental. Los escasos recursos para la compra de vivienda ameritan la búsqueda de alternativas menos costosas de construcción, que a su vez incidan en la preservación del medio ambiente, el ahorro energético y el desarrollo sostenible. A partir de las necesidades detectadas en la investigación, la construcción de viviendas bioclimáticas permite el aprovechamiento al máximo de los recursos, reduce el impacto ambiental y reduce la huella ecológica, además, las condiciones climáticas de la zona costa del Ecuador incentivan al uso de principios bioclimáticos en el diseño y construcción de viviendas.

Uno de los materiales que hace que las viviendas sean sostenibles y que ha demostrado tener propiedades físico mecánicas ideales para la construcción es la caña guadúa. Esta se produce en mayor cantidad en la zona de la costa y en especial en la provincia de Manabí, lo que hace de este componente un material asequible que contribuye además a promover el desarrollo local. Para mitigar el desconocimiento sobre normativas, subsidios y un diseño arquitectónico viable, se presentó la memoria descriptiva de un proyecto de construcción de vivienda de interés social, que puede servir de guía para ser presentado. 
El mayor inconveniente encontrado a la hora de realizar el diseño, fue el ajustarse al presupuesto, considerado este muy bajo y repercutiendo en la calidad final que tendría la obra, de ejecutarse; esto contribuye a reforzar el paradigma colectivo que refiere a las viviendas de caña asociadas a la pobreza. La propuesta planteada se ajusta a los parámetros exigidos por los organismos competentes en cuanto a diseño y presupuesto para el otorgamiento del $100 \%$ de su subsidio. La propuesta planteada sigue los principios de la bioconstrucción, promueve el rescate de la arquitectura vernácula y contribuye con la reducción de la huella ecológica por construcciones.

\section{Recomendaciones:}

Se deberán indagar los requerimientos del Gobierno Autónomo Descentralizado donde se va a construir la vivienda para estar al día con ellos. La realización de las viviendas debe contar con la debida planificación, en especial para la compra del material que debe darse varios meses antes de su inicio. Las tareas relacionadas a la preparación del material, fabricación, construcción, montaje y mantenimiento de la vivienda deben estar regidas por prácticas establecidas y aceptadas por la ingeniería y la arquitectura. Los materiales seleccionados para la construcción deben ser los idóneos y estar acordes con las normas mencionadas en el cuerpo de esta investigación y otras que los profesionales que realicen el diseño y ejecuten la obra consideren convenientes. Debe proporcionarse al proveedor de la caña guadúa las medidas y especificaciones de calidad requeridas. Se debe exigir garantía de las cañas adquiridas, en especial solicitar que se respete el número de culmos pedidos, las especificaciones de medidas, grosores, madurez, corte, porcentaje de humedad adecuado del material a pie de obra, método de preservación usado y adecuado secado. Se debe exigir al constructor el debido almacenamiento de las cañas acorde a la normativa.

En lo posible, debe adquirirse un 20\% más de los culmos de los calculados para la construcción (no incluidos en el presupuesto), esto por imperfecciones que puedan presentar las cañas como curvas pronunciadas, rajaduras, entre otros. Debido a que se contempla el uso más recurrente de la caña guadúa, se sugiere a los organismos competentes plantear un proyecto en el que se busque la manera de certificar a los productores en los procesos de extracción y preservado, dureza y durabilidad. Se debe, antes de la ejecución de la obra, hacer un reconocimiento más exhaustivo del sitio, velar por la buena limpieza del terreno, verificar las condiciones de seguridad de la zona y de los edificios o construcciones colindantes, así como contar con resguardo para los materiales (en especial de las cañas, con una cubierta provisional), resguardo para el personal que laborará en la obra, una acometida eléctrica provisional y suministro de agua.

Los culmos, previa su utilización, deben ser limpiados cuidadosamente con telas, esponjas, cepillos no abrasivos, a manera de no causarles daño. Durante el proceso de construcción, no se deben maltratar los culmos con impactos, aplastamientos o caídas que puedan afectar sus características físico-mecánicas. Los culmos a ser destinados a la parte estructural, nunca debieron ser usados anteriormente. Deben seguirse pautas de diseño arquitectónico que garanticen estabilidad, seguridad y durabilidad de la vivienda. Respetar las normas relativas a los cimientos y sobrecimientos, a los anclajes de los culmos a los sobrecimientos, a los debidos cortes de uniones entre culmos, a uniones entre piezas estructurales, a los elementos constructivos (columnas, vigas, paneles, entrepiso, cubierta), a acabados, y a otras reflejadas en la normativa Ministerio de Desarrollo Urbano y Vivienda (2016).

La construcción de la vivienda debe realizarse por personal capacitado y bajo la dirección de un profesional que conozca la normativa requerida. Debe proporcionarse al constructor los diseños 
arquitectónicos, de instalaciones, presupuesto, análisis de costos, estudios del suelo, detalles constructivos y las especificaciones técnicas. Se debe garantizar que el trabajo se realice bajo estrictas normas de seguridad, tanto del manejo de materiales y manejo ecológico de desechos, como de la seguridad de los trabajadores. Los andamios no deben anclarse ni estar conectados a la estructura de la edificación. Se debe velar que las instalaciones hidrosanitarias, eléctricas, electrónicas y mecánicas no atraviesen o comprometan a los culmos que forman parte del sistema estructural. Contar con botiquín de primeros auxilios durante la ejecución de la obra.

Se deben seguir las indicaciones de colocación del mobiliario ya que están basadas en los principios del Feng Shui, así como los colores sugeridos. Se recomienda que estos colores sean claros para permitir que la luz se refleje y permita el refrescamiento de los espacios. Se recomienda colocar vegetación alrededor de la casa que sea autóctona. Debe asesorarse a los futuros habitantes de la vivienda sobre el mantenimiento preventivo de la misma y sobre el respeto por el uso para el que fue diseñada: vivienda unifamiliar. La frecuencia de mantenimiento dependerá de las condiciones ambientales como la temperatura, humedad y grado de exposición al sol; también dependerá del grado de fricción de la película protectora y del nivel de exigencia estructural de los culmos. Se sugiere a los organismos competentes, ofertar proyectos que busquen la asignación de recursos financieros para apoyar investigaciones en cuanto nuevos usos y aplicaciones de la caña guadúa, mejora de sus propiedades, así como la operacionalización de procesos de siembra, extracción y preparación del material, que garanticen su calidad durante todo el ciclo de vida y uso de la misma.

\section{Contribuciones de los autores}

En concordancia con la taxonomía establecida internacionalmente para la asignación de créditos a autores de artículos científicos (https://casrai.org/credit/). Los autores declaran sus contribuciones en la siguiente matriz:

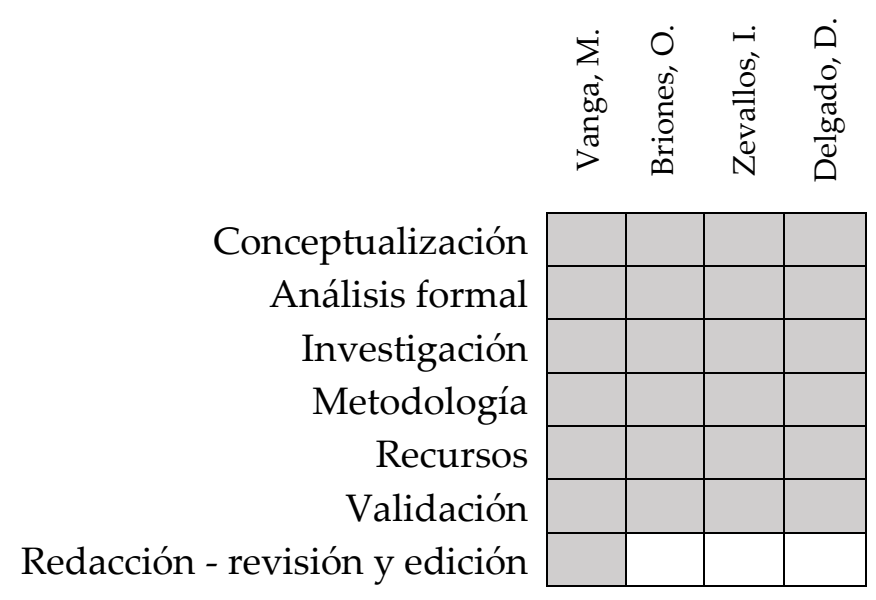

\section{Conflicto de Interés}

Los autores declaramos que no existen conflictos de interés de naturaleza alguna.

\section{Referencias}

Ardilas, C., Folgueras, M., \& Fernández, F. (2020). Oxidative pyrolysis of Guadua angustifolia Kunth. Energy Reports, 6(1), 738-743. https://doi.org/10.1016/j.egyr.2019.09.057 
Britez, C., Pacheco, S., Levy, S., \& Helene, P. (2015). Uso del hormigón de altas prestaciones en columnas estructurales con vistas a la sostenibilidad. Revista ALCONPAT, 5(1), 74-83. Recuperado de http://www.scielo.org.mx/scielo.php?script=sci_arttext\&pid=S2007-68352015000100007

Campos, M. O. (2017). Métodos de investigación académica. Costa Rica: Universidad de Costa Rica. http://www.kerwa.ucr.ac.cr/bitstream/handle/10669/76783/Campos\%20Ocampo,\%20Melvin.\%202017. \%20M\%C3\%A9todos\%20de\%20Investigaci\%C3\%B3n\%20acad\%C3\%A9mica.\%20(versi\%C3\%B3n\%201 .1).\%20Sede\%20de\%20Occidente, $\% 20 \mathrm{UCR}$.pdf?sequence $=1$

Chiriboga, I. M. (2018). Diseño Arquitectónico de un Conjunto Habitacional de interés social con estrategias sostenibles para el GAD del Cantón Pedernales, en la Provincia de Manabí (Tesis previa a la obtención del título de Arquitecto). Universidad Tecnológica Equinoccial, Quito, Ecuador. Recuperado de http://repositorio.ute.edu.ec/handle/123456789/18760

Colegio de Arquitectos del Ecuador - Pichincha (2017). Arquitecto japonés muestra el uso de material convencional para elaboración de casas emergentes. Disponible en https://www.cae.org.ec/arquitecto-japones-muestrael-uso-de-material-convencional-para-elaboracion-de-casas-emergentes/

Cortes, M. F., Hernández, C. E., Guerrero, C. I., \& Vega, R. A. (2011). Captación y aprovechamiento del agua de lluvia. Kuxulkab, 17(33), 73-75. https://doi.org/10.19136/kuxulkab.a17n33.366

Decreto Ejecutivo № 681 (2019). Reglamento para el acceso a subsidios e incentivos del programa de vivienda de interés social y público en el marco de la intervención emblemática "Casa para todos". Ecuador. Recuperado de https://www.habitatyvivienda.gob.ec/wp-content/uploads/downloads/2019/07/681-Reglamento-parael-acceso-a-VIS.pdf

Delgado, G. (2017). Ecología y ambiente: Diseño y sustentabilidad en construcciones con caña guadúa. DAYA. Diseño, Arte y Arquitectura, (2), 75-93. https://doi.org/10.33324/daya.v1i2.32

EcoHabitar (2020). El CO2 derivado de la construcción y el papel captador del bambú Guadúa como material alternativo. Recuperado de https://ecohabitar.org/el-co2-derivado-de-la-construccion-y-el-papel-captador-delbambu-guadua-como-material-alternativo/

Escudero, J. R. (2018). Propuesta arquitectónica de un resort campestre con sistema de ventilación cruzada en la Campiña, Chimbote (Tesis para obtener el título profesional de Arquitecto). Universidad San Pedro, Chimbote, Perú. Recuperado de http://repositorio.usanpedro.edu.pe/handle/USANPEDRO/8408

Espejo, C. (2015). Propuesta de vivienda bioclimática para el Ministerio de Desarrollo Urbano y Vivienda (MIDUVI), en la Parroquia Rural de Malacatos del Cantón y Provincia de Loja (Tesis de grado para la obtención del título de Arquitecto). Universidad Internacional del Ecuador, Loja, Ecuador. Recuperado de http://repositorio.uide.edu.ec/handle/37000/1024

Fernández, N. V. (2020). Certificación de plantaciones y cadena de custodia de bambú gigante (Dendrocalamus asper) y caña guadúa (Guadua angustifolia Kunth), bajo los criterios del Forest Stewardship Council (FSC) (Trabajo para la obtención del Título de Ingeniero Forestal). Universidad Técnica del Norte, Ibarra, Ecuador. http://repositorio.utn.edu.ec/handle/123456789/10370

Ferro, J. M. (2015). Venta y alquiler de bienes inmuebles para no iniciados. Madrid, España: CreateSpace Independent Publishing Platform. Recuperado de https://www.amazon.com/Venta-alquiler-bienesinmuebles-iniciados/dp/1514378868

Garavito, L. L. (2020). Análisis normativo del manejo sostenible y el aprovechamiento productivo del bambú-Guadua en los Departamentos del Quindío y Cundinamarca en Colombia (Tesis de Maestría). Universidad Jorge Tadeo Lozano, Bogotá, Colombia. Recuperado de

http://expeditiorepositorio.utadeo.edu.co/bitstream/handle/20.500.12010/13240/Trabajo\%20de\%20grad o.pdf?sequence $=1 \&$ isAllowed $=y$ 
García, J. R., García, F., \& Saraví, N. (2015). Sostener-Cerrar-Construir: Introducción a la materialidad arquitectónica. La Plata, Argentina: Editorial de la Universidad Nacional de La Plata. https://doi.org/10.35537/10915/46682

Gahona, E., \& Montenegro, J. (2016). Propuesta de viviendas económicas para reasentamientos humanos utilizando microhormigón y caña guadua (Proyecto de grado previo a la obtención del título de Ingeniero Civil). Escuela Superior Politécnica del Litoral. Guayaquil. Ecuador. http://www.dspace.espol.edu.ec/xmlui/handle/123456789/40180

Herrera, M. B., \& Oyola, C. A. (2020). Propuesta de diseño general e implementación del uso de materiales eficientes en la construcción de un módulo de vivienda sostenible en Sondorillo - Huancabamba - Piura (Tesis para optar el título profesional de Ingeniero Civil). Universidad peruana de Ciencias Aplicadas, Lima, Perú. http://hdl.handle.net/10757/652827

López, L. (2015). Norma Andina para diseño y construcción de casas de uno y dos pisos en bahareque encementado. Quito, Ecuador: Red Internacional para el desarrollo del bambú y el ratán, Recuperado de https://www.cevaconsult.com/wp-content/uploads/2018/05/Bahareque-Encementado.pdf

Melo, M., \& Valenzuela, J. (2021). Análisis de políticas para el desarrollo del bambú en las provincias de Napo, Pastaza y Morona Santiago, Ecuador. Ecuador: Organización Internacional del Bambú y el Ratán. Recuperado de https://www.inbar.int/wp-content/uploads/2021/02/Analisis-de-Politicas-para-el-Desarrollo-delBambu-en-las-Provincias-de-Napo-Pastaza-y-Morona-Santiago-Ecuador.pdf

Ministerio de Agricultura y Ganadería (2018). Estrategia nacional del bambú 2018-2022: Lineamientos para un desarrollo verde e inclusivo. Quito, Ecuador: Ministerio de Agricultura y Ganadería - Red Internacional del Bambú y el Ratán.

https://bambuecuador.files.wordpress.com/2019/03/estrategia-nacional-bambc3ba-2018-2022versic3b3n-resumida.pdf

Ministerio de Desarrollo Urbano y Vivienda (2019). Acuerdo No. 004-19: Reglamento para validación de tipologías y planes para proyectos de vivienda de interés social. Quito, Ecuador: Ministerio de Desarrollo Urbano y Vivienda. Recuperado de https:/www.habitatyvivienda.gob.ec/wp-content/uploads/downloads/2019/03/Acuedo-No-004-19Reglamento-para-validacion-de-tipologias-planes-masa-proyectos-de-vivienda-interes-social-1.pdf

Ministerio de Desarrollo Urbano y Vivienda (2018). Proyecto de vivienda Casa para Todos - CPT. Ecuador: Ministerio de Desarrollo Urbano y Vivienda. Recuperado de https:/www.habitatyvivienda.gob.ec/wpcontent/uploads/downloads/2019/06/PROYECTO-DE-VIVIENDA-CASA-PARA-TODOS.pdf

Ministerio de Desarrollo Urbano y Vivienda (2016). Estructuras de Guadúa (GaK). Ecuador: Ministerio de Desarrollo Urbano y Vivienda. Recuperado de https:/www.habitatyvivienda.gob.ec/wpcontent/uploads/downloads/2017/04/NEC-SE-GUADUA-VERSION-FINAL-WEB-MAR-2017.pdf

Ministerio del Trabajo (2020). Acuerdo No. MDT-2020-249. Quito, Ecuador: Ministerio del Trabajo. Recuperado de https://www.fielweb.com/App_Themes/InformacionInteres/MDT-2020-249.pdf

Molina, S. (2019). Consumo de agua dura en la población de las irrigaciones de la parte baja del río Chili-Arequipa 2016 (Tesis para obtener el grado académico de Maestra en Gestión Ambiental). Universidad Nacional Federico Villareal, Lima, Perú. Recuperado de http://repositorio.unfv.edu.pe/handle/UNFV/3642

Morán, J. (2011). LA GUADÚA: EL ORO DE LOS ANDES. Recuperado de https://es.slideshare.net/vivaguadua2011/11-jorge-moran

Morán, J. (2015). Construir con Bambú (Caña de Guayaquil) - Manual de construcción (3ra. ed.). Lima, Perú: International Bamboo and Rattan Organization (INBAR). Recuperado de https://www.sheltercluster.org/sites/default/files/docs/construir_con_bambu_peru.pdf 
Muñoz, C., \& Quiroz, F. (2014). Análisis de Ciclo de Vida en la determinación de la energía contenida y la huella de carbono en el proceso de fabricación del hormigón premezclado. Caso estudio planta productora Región del Bío Bío, Chile. Revista Hábitat Sustentable, 4(2), 16-25. http://revistas.ubiobio.cl/index.php/RHS/article/view/447

Orengo, S. (2019). La relación entre las teorías de construcción bioclimática y el Feng Shui (Trabajo de fin de Grado). Universidad Politécnica de Valencia, Valencia, España. https://riunet.upv.es/handle/10251/135093

Poveda, G., Franco, Z., Pilco, M., Suriaga, M., Rivera, G., \& Sacoto, D. (2016). Construcción de viviendas con caña Guadua en el Ecuador, una realidad amigable y sustentable. Artículo presentado en el I Congreso Internacional online Filosofía de la Sustentabilidad de Vivienda Tradicional "Transformando comunidades hacia el desarrollo local." Universidad de Guayaquil, Guayaquil, Ecuador. Recuperado de https://www.eumed.net/libros-gratis/actas/2016/filosofia/construccion-viviendas-guido-poveda.pdf

Quispe, C. (2016). Estudio técnico, económico de tratamiento de agua dura mediante desincrustante magnético para riego presurizado (Tesis para obtener el título de profesional de: Ingeniero Agrícola). Universidad Nacional de San Cristóbal de Huamanga, Ayacucho, Perú.

http://repositorio.unsch.edu.pe/handle/UNSCH/3174

Rivadeneira, F. (2017). Uso de la Caña Guadúa: Arquitectura vernácula en restaurantes de la ciudad de Portoviejo, Ecuador. En M. Bravo (compilador). Escritos en la Facultad, 13(130). 33-34. Recuperado de https://fido.palermo.edu/servicios_dyc/publicacionesdc/vista/detalle_articulo.php?id_libro=652\&id_ar ticulo $=13633$

Rodríguez, A., \& Morales, E. (2008). El Bambú como material estructural: análisis de un caso práctico (Bachelor Thesis). Universidad de Girona, Girona, España. Recuperado de http://hdl.handle.net/10256/1128

Rubio, C. (2019). Bioconstrucción: Parámetros que configuran una relectura contemporánea de la Arquitectura Vernácula (Trabajo Fin de Grado). Universidad Politécnica de Madrid, Madrid, España. http://oa.upm.es/54314/

Sánchez, P. A. (2020). Bioconstrucción a detalle: una experiencia compartida. Revista Gremiun, 7(14), $185-188$. https:/editorialrestauro.com.mx/gremium/index.php/gremium/article/view/94

Trujillo, A., Nieto, N., Vanegas, O., \& Díaz, F. (2020). Utilización de la Guadua angustifolia Kunth en el diseño arquitectónico y estructural de una vivienda de interés social rural. En E. Serna (Ed). Investigación formativa en Ingeniería, (4a. ed.), (pp. 97-108). Medellín, Colombia: Instituto Antioqueño de Investigación. https://www.researchgate.net/profile/Edgar-Serna-

M/publication/344418700_Investigacion_formativa_en_ingenieria_4/links/5f739a03a6fdcc008648239a/I nvestigacion-formativa-en-ingenieria-4.pdf\#page=106

Vázquez, K., \& Guillén, V., (2016). Análisis del inventario del ciclo de vida en la determinación de la energía contenida y las emisiones de CO2 en el proceso de fabricación del hormigón premezclado; caso de estudio: Planta Premezcladora de la ciudad de Cuenca (Artículo científico previo a la obtención del grado de Magister en Construcciones). Universidad de Cuenca, Cuenca, Ecuador. http://dspace.ucuenca.edu.ec/handle/123456789/26618

Yang, H. (2018). Feng Shui y espacio (Tesis Doctoral). Universidad Complutense de Madrid. Madrid, España. Recuperado de https://eprints.ucm.es/id/eprint/49602/

Yann, B. (2020). Logros y desafíos de la construcción con bambú en el Perú: Reflexiones sobre experiencias contemporáneas en la Costa del Perú. Bambú para la Ciencia, Innovación y Tecnología, (3). 23-29. Recuperado de http://www.lamolina.edu.pe/FACULTAD/forestales/revistas/CIB/BAMBUCYT_TERCERA_EDICION. pdf 